\title{
Organosolv Lignin Properties and Their Effects on Enzymatic Hydrolysis
}

\author{
Yang Huang, ${ }^{\mathrm{a}, \mathrm{c}}$ Chenhuan Lai, ${ }^{\mathrm{a}}$ Shaolong Sun, ${ }^{\mathrm{d}}$ Qiang Yong, ${ }^{\mathrm{a}, *}$ Brian K. Via, ${ }^{\mathrm{c}}$ and \\ Maobing $\mathrm{Tu}^{\mathrm{b}, *}$
}

\begin{abstract}
Lignin plays a crucial role in enzymatic hydrolysis of lignocellulosic biomass. To evaluate the correlation between lignin properties and its effects on enzymatic hydrolysis, five organosolv lignins (OLs) were isolated from woody biomass, and their physico-chemical properties and structural features were characterized. The effects of OL addition on enzymatic hydrolysis of microcrystalline cellulose (pure cellulose) were assessed first, which showed their disparate effects. The addition of three OLs increased the $72 \mathrm{~h}$ hydrolysis yield by $7.4 \%$ to $10.1 \%$, while the addition of other two OLs reduced the $72 \mathrm{~h}$ hydrolysis yield by $3.2 \%$ to $20.4 \%$. A strong correlation between the enzyme distribution coefficient on lignins and the $72 \mathrm{~h}$ hydrolysis yields indicated that the enzyme-lignin interaction played a significant role in determining the lignin effects. More importantly, a correlation between lignin properties (hydrophobicity, zeta potential, and particle size) and the enzyme distribution coefficient was established. Identifying the key lignin properties will give insights to reduce the lignin inhibition by altering the lignin properties, thereby promoting enzymatic hydrolysis of lignocellulose.
\end{abstract}

Keywords: Organosolv lignin; Enzymatic hydrolysis; Enzyme distribution coefficient; Hydrophobicity; Zeta potential; 2D HSQC NMR

Contact information: a: Jiangsu Co-Innovation Center of Efficient Processing and Utilization of Forest Resources, College of Chemical Engineering, Nanjing Forestry University, Nanjing 210037, China; b: Department of Biomedical, Chemical and Environmental Engineering, University of Cincinnati, 2901 Woodside Drive, Cincinnati OH 45221, United States; c: Forest Products Laboratory and Center for Bioenergy and Bioproducts, Auburn University, 520 Devall Drive, Auburn, AL 36849, United States; d: College of Natural Resources and Environment, South China Agricultural University, Guangzhou 510642, China; *Corresponding authors: swhx@njfu.com.cn (Q.Yong); tumg@uc.edu (M.Tu)

\section{INTRODUCTION}

Lignification of cell walls in plants contributes to their mechanical strength and to their resistance to exoteric degradation from microorganisms or enzymes (Grabber et al. 2004). Lignin is a heterogeneous polymer composed of phenylpropane units, which enwraps cellulose and hemicelluloses. It is commonly believed that the presence of lignin in the lignocellulosic matrix significantly hinders the bioconversion of lignocelluloses, especially the enzymatic hydrolysis to valuable fuels and chemicals. It forms a physical barrier to enzyme access and non-productively adsorbs enzyme (Kumar et al. 2012; Li and Zheng 2017). Thus it imparts a major economical bottleneck during biorefinery processing.

To alleviate the negative effects of lignin on enzymatic hydrolysis, numerous studies have examined the factors determining the lignin inhibition (Kumar et al. 2012; Li et al. 2016; Li and Zheng 2017; Yoo et al. 2020). Lignin properties such as lignin content, aromatic subunit composition, interunit linkage contents, functional groups contents, 
molecular weight, and hydrophobicity are commonly determined (Yoo et al. 2020). Among these properties, the effect of lignin content on enzymatic hydrolysis has been extensively investigated by preparing a series of lignocellulosic substrates with various delignification degrees. The higher extent of lignin removal resulted in higher cellulose accessibility of cellulose, thus achieving the better enzymatic digestibility (Öhgren et al. 2007). This demonstrated that the lignin content is negatively correlated with enzymatic hydrolysis (Öhgren et al. 2007; Yu et al. 2014; Li and Zheng 2017). However, chemical structural changes in lignin occur during delignification, which might affect the evaluation of lignin content effect on enzymatic hydrolysis.

Isolated lignin can be added during the enzymatic hydrolysis of pure cellulose to investigate roles of lignin in hydrolysis (Lai et al. 2014; Ying et al. 2018). Even if the same amount of lignin is added, the lignin inhibition on enzymatic hydrolysis varies with the types/origin of lignins, mainly due to the various lignin properties (Li et al. 2016; Li and Zheng 2017). Normally, the addition of isolated lignins inhibits hydrolysis by enzyme nonproductive binding or/and by deactivating the enzyme (Yu et al. 2014; Sun et al. 2016). Recently, it has been reported that the addition of isolated lignins shows negligible or even positive effects on enzymatic hydrolysis. Switchgrass lignin derived from dilute acidpretreatment has little effect on the rates and extents of cellulose saccharification (MeunierGoddik and Penner 1999). Extractable lignin and ethanol organosolv lignin from organosolv-pretreated sweetgum facilitate the enzymatic hydrolysis process of both cellulose and lignocellulose (Lai et al. 2014). Similar effects have been reported for modified lignins, such as lignosulfonates, $\gamma$-carboxylated lignin, and hydroxypropylated lignin (Pan 2008; Nakagame et al. 2011; Wang et al. 2013). However, the key factors dominating the positive/negative effects of lignin on enzymatic hydrolysis are unknown.

The interaction between enzymes and lignins plays an essential role in affecting the enzymatic hydrolysis of pure cellulose with the lignin addition (Lou et al. 2013; Lai et al. 2014). The lignin-enzyme interactions are mediated via hydrophobic interactions, electrostatic interactions, and hydrogen bond interactions (Berlin et al. 2006). Therefore, these interactions could be dominated by the lignin physico-chemical properties, including lignin hydrophobicity and surface charge (Lai et al. 2014). Logically, a higher lignin hydrophobicity and a lesser surface charge in lignin will result in stronger enzyme binding on lignins (Li and Zheng 2017). Moreover, the physico-chemical properties of lignin are governed by its chemical structure, such as the ratio of syringyl and guaiacyl units (S/G ratio), lignin inter-linkage contents, and functional groups (Yu et al. 2014; Yoo et al. 2018). The S/G ratio of lignin has an important role in enzymatic hydrolysis (Yoo et al. 2018). Pan (2008) suggested that the hydroxyl-propylation of phenolic hydroxyl groups could significantly remove the lignin inhibition. Therefore, characterization of lignin physicochemical properties and chemical structure is important for understanding the role of lignins in enzymatic hydrolysis.

A previous study investigated the effects of lignins isolated from sulfuric acid catalyzed organosolv pretreatment on enzymatic hydrolysis (Huang et al. 2017). However, the hydrochloric acid catalyzed hydrolysis of the woody biomass has not been reported yet. More importantly, it has been reported that pretreatment with hydrochloric acid as catalyst was more efficient than sulfuric acid under the same constraints (Adel et al. 2010; HerediaOlea et al. 2012). Indeed, the authors' study confirmed that the application of hydrochloric acid achieved better delignification performance in organosolv pretreatment, as compared to sulfuric acid (data not shown). Therefore, the objective of this study is to investigate the effects of lignins generated from hydrochloric acid catalyzed organosolv pretreatment on 
enzymatic hydrolysis. In addition, the properties of OLs isolated from this pretreatment were compared to those of OLs isolated from sulfuric acid catalyzed pretreatment, as well as their effects on enzymatic hydrolysis. Firstly, hydrochloric acid catalyzed organosolv pretreatment was applied in five different woody biomasses. The corresponding five OLs were isolated, and their physico-chemical properties, including hydrophobicity, zeta potential, and particle size, were assessed. The chemical structures of these five OLs were also analyzed using 2D HSQC NMR analysis. Then, the effects of OLs addition on enzymatic hydrolysis of pure cellulose (microcrystalline cellulose) were investigated. Besides, to explore the underlying reasons for their disparate effects on enzymatic hydrolysis, the adsorption behaviors between lignins and enzymes were assessed by Langmuir adsorption isotherms. Finally, the distribution coefficient, a parameter from Langmuir adsorption isotherms, was correlated with physico-chemical properties and chemical structures of lignins, to figure out the key lignin features affecting the enzymatic hydrolysis. Results could give insights to reduce the lignin inhibition, or even to reverse the lignin effects into promoting effects on enzymatic hydrolysis.

\section{EXPERIMENTAL}

\section{Materials and Enzymes}

Wood chips of cottonwood, black willow, aspen, eucalyptus, and loblolly pine were kindly provided by Forest Products Laboratory at Auburn University. Microcrystalline cellulose (Avicel PH-101, MCC) was purchased from Sigma-Aldrich (St. Louis, MO, USA). Cellulase (Cellic CTec2, Novozymes, Franklinton, NC, USA) with $126.21 \mathrm{FPU} / \mathrm{mL}$ of filter paper activity was used in the enzymatic hydrolysis experiments. Cellulase (C2730, Sigma-Aldrich) with $76.61 \mathrm{FPU} / \mathrm{mL}$ of filter paper activity was used in the enzyme adsorption isotherm determination.

\section{Preparation of Organosolv Lignins}

To prepare OLs, organosolv pretreatment of woody biomass was first carried out, and then the OLs were collected from the obtained organosolv spent liquor. Briefly, the wood chips from hardwood biomass (cottonwood, black willow, aspen, and eucalyptus) were cooked with $65 \%(\mathrm{v} / \mathrm{v})$ aqueous ethanol solution and $0.75 \%(\mathrm{w} / \mathrm{w})$ hydrochloric acid, in a solid to liquid ratio of $1: 7(\mathrm{w} / \mathrm{v})$, at $160{ }^{\circ} \mathrm{C}$ for $60 \mathrm{~min}$. The wood chips from softwood (loblolly pine) were cooked under the same conditions with the pretreatment temperature of $170^{\circ} \mathrm{C}$. After cooking, the organosolv spent liquor was collected by filtration and diluted with 3-fold volumes of water. The OLs were precipitated from the spent liquor, collected on Whatman No. 1 filter paper, washed with water, and air-dried. Hereby, the OLs prepared from cottonwood, black willow, aspen, eucalyptus, and loblolly pine were referred to as OL-CW, OL-BW, OL-AS, OL-EH, and OL-LP, respectively.

\section{Enzymatic Hydrolysis and Enzyme Distribution Determination}

Enzymatic hydrolysis of MCC was performed at $2 \%$ glucan (w/v), $\mathrm{pH} 4.8,50{ }^{\circ} \mathrm{C}$, and $150 \mathrm{rpm}$ for $72 \mathrm{~h}$, as described previously (Huang et al. 2017). The cellulase (Cellic CTec2) loading of $5 \mathrm{FPU} / \mathrm{g}$ glucan was applied in all enzymatic hydrolysis experiments. To evaluate the effects of OLs addition on enzymatic hydrolysis, $4 \mathrm{~g} / \mathrm{L}$ OLs were added into the enzymatic hydrolysis of MCC prior to the addition of cellulase. Samples were taken throughout the hydrolysis process. The concentrations of glucose in the hydrolysis 
supernatants were determined by high-performance liquid chromatography (HPLC) with Aminex HPX-87P column. The hydrolysis yields were calculated based on the released glucose and presented as a percentage of the theoretical glucose available in MCC. To estimate the effects of OLs on enzyme distribution during the hydrolysis process, the free enzyme concentrations in the hydrolysis supernatants were determined using the Bradford assay (Bradford 1976) and presented as the percentage of the total protein concentrations. All enzymatic hydrolysis experiments were run in duplicate.

\section{Cellulase Adsorption Isotherms}

To assess the binding behavior between enzyme and lignin preparations, cellulase adsorption experiments were performed in $5 \mathrm{~mL}$ of $0.05 \mathrm{M}$ citrate buffer $(\mathrm{pH} 4.8)$ containing 2\% (w/v) lignin samples. Cellulase C2730 was used instead of Cellic CTec2, due to its low $\beta$-glucosidase content. Cellulase $\mathrm{C} 2730$ with a protein concentration range of $0.01 \mathrm{mg} / \mathrm{L}$ to $0.4 \mathrm{mg} / \mathrm{mL}$ were added, and the mixture was incubated at $4{ }^{\circ} \mathrm{C}$ and 150 rpm for $3 \mathrm{~h}$. After the incubation, the supernatant was collected by centrifugation. The content of free enzyme protein in the supernatant was quantified by Bradford assay (Bradford 1976). The content of adsorbed enzyme on lignin samples was calculated based on the difference between the free enzyme content and the total enzyme content. Langmuir adsorption isotherm (Eq. 1) was fitted to the adsorption data,

$$
\Gamma=\frac{\Gamma_{\max } K C}{1+K C}
$$

where $C(\mathrm{mg} / \mathrm{mL})$ is the concentration of free enzyme protein in solution, $\Gamma(\mathrm{mg} / \mathrm{g})$ is the amount of adsorbed protein, $\Gamma_{\max }(\mathrm{mg} / \mathrm{g})$ is the maximal adsorbed protein, and $K(\mathrm{~mL} / \mathrm{mg})$ is the Langmuir constant.

The distribution coefficient $(R, \mathrm{~L} / \mathrm{g})$, which was used to estimate the binding strength between enzyme and lignin (Nakagame et al. 2011), was calculated with Eq. 2 .

$$
R=\Gamma_{\max } K
$$

\section{Lignin Characterization}

\section{Chemical compositional analysis}

The carbohydrates, acid insoluble lignin (AIL), and acid soluble lignin (ASL) of the five OLs were determined according to National Renewable Energy Laboratory (NREL) LAP002 method (Sluiter et al. 2012). Briefly, the lignins were subjected to a twostep acid hydrolysis. The carbohydrates contents of lignins were determined by measuring the concentrations of the released sugars with the HPLC, as mentioned previously. The AIL contents were determined by weighing the solid residues after the two-step acid hydrolysis. The ASL contents were determined by measuring the UV absorbance of the acid hydrolysates. The compositional analysis was carried out in duplicate. The results were shown as the average of two replicates.

\section{Hydrophobicity determination}

Lignin hydrophobicity was determined by measuring the distribution of hydrophobic dye (Rose Bengal) on lignins, following the previous reports of Lai et al. (2014). Briefly, lignins with increasing concentrations of $2 \mathrm{~g} / \mathrm{L}$ to $10 \mathrm{~g} / \mathrm{L}$ were mixed with $40 \mathrm{mg} / \mathrm{L}$ rose bengal at $\mathrm{pH} 4.8$ and incubated at $50{ }^{\circ} \mathrm{C}, 150 \mathrm{rpm}$ for $2 \mathrm{~h}$. After the incubation, the supernatant solutions were obtained by centrifugation, and the free dye content in the supernatant was determined by measuring the UV absorbance at $543 \mathrm{~nm}$. The content of 
adsorbed dye on the lignin surface was quantified based on the difference between the total dye content and the free dye content. Then the partitioning quotient (PQ) was calculated as the ratio of the amount of adsorbed dye on lignins to the amount of dye in supernatants. The PQ was then plotted against the increasing lignin concentration. The slopes of the straight lines were regarded as a measure of the surface hydrophobicity of lignin $(\mathrm{L} / \mathrm{g})$.

\section{Zeta potential determination}

Prior to the zeta potential determination, the lignin sample $(1 \mathrm{mg})$ was suspended in $1 \mathrm{~mL}$ of $50 \mathrm{mM}$ citrate buffer solution ( $\mathrm{pH} 4.8$ ) in a measurement cell, since the enzymatic hydrolysis/adsorption was carried out in the same buffer solution. The zeta potential of the lignin was measured with the Zetasizer (Nano-ZS, Malvern Instruments Ltd, Worcestershire, UK) and analyzed by Dispersion Technology Software. The measurements were repeated at least three times.

\section{Particle size determination}

Field emission scanning electron microscopy analysis was carried out on the lignin samples using a JEOL 7000F instrument (Tokyo, Japan) operated at $20.0 \mathrm{KV}$. The samples were coated with a thin gold layer $(50 \mathrm{~nm})$, and their particle size of these lignin pellets was calculated using ImageJ software (https://imagej.nih.gov/ij/index.html)

\section{D HSQC NMR spectroscopy analysis}

The 2D heteronuclear single quantum correlation (2D HSQC) NMR analysis was performed on a Bruker $600 \mathrm{MHz}$ spectrometer (Karlsruhe, Germany) at $25^{\circ} \mathrm{C}$ with the Bruker pulse program "hsqcetgp" as described previously (Huang et al. 2017). Approximately $60 \mathrm{mg}$ of OLs were dissolved in $0.5 \mathrm{~mL}$ of DMSO-d6. The central DMSO solvent peak was used as an internal reference for all samples. The HSQC NMR parameters used were listed as below: the ${ }^{1} \mathrm{H}$ dimension $\left(\mathrm{F}_{2}\right)$ was acquired from $10 \mathrm{ppm}$ to $0 \mathrm{ppm}$ with 4096 data points, the ${ }^{13} \mathrm{C}$ dimension $\left(\mathrm{F}_{1}\right)$ was obtained from $200 \mathrm{ppm}$ to $0 \mathrm{ppm}$ with 64 scans, and 256 increments. Acquisition time of $0.24 \mathrm{~s}$ and $0.028 \mathrm{~s}$ were used for ${ }^{1} \mathrm{H}$ and ${ }^{13} \mathrm{C}$, respectively. The total acquisition time used was $17.5 \mathrm{~h}$. The spectra were analyzed with Topspin 2.1 software (Bruker, Karlsruhe, Germany).

\section{RESULTS AND DISCUSSION}

\section{Organosolv Lignins Characterization}

Five OLs (OL-CW, OL-BW, OL-AS, OL-EH, and OL-LP) were prepared from organosolv pretreatment of various woody biomass (cottonwood, black willow, aspen, eucalyptus, and loblolly pine, respectively), and then subjected to chemical compositional analysis, characterization of physico-chemical properties, and 2D HSQC NMR analysis. The chemical compositional analysis results showed that the AIL contents were $92.1 \%$ to $97.0 \%$ in five OLs, while the polysaccharides (glucan, xylan, and mannan) contents were less than $3.0 \%$ (Table 1). This indicated the high purity of five OLs, which suggested that they can be used as representative samples to study the relation between lignin properties and its effects on enzymatic hydrolysis without the interference from other components (Lai et al. 2014). As compared with the sulfuric acid catalyzed organosolv pretreatment (Huang et al. 2017), hydrochloric acid catalyzed organosolv pretreatment removed the lignin more efficiently, but it had the similar effects on the purity of OLs. 
Table 1. The Chemical Composition of Organosolv Lignins (\%)

\begin{tabular}{|c|c|c|c|c|c|}
\hline Lignins & AlL & ASL & Glucan & Xylan & Mannan \\
\hline OL-CW & $92.12 \pm 0.25^{*}$ & $1.22 \pm 0.01$ & $0.07 \pm 0.00$ & $0.45 \pm 0.01$ & $2.80 \pm 0.02$ \\
\hline OL-BW & $93.04 \pm 0.36$ & $1.24 \pm 0.02$ & $0.07 \pm 0.00$ & $0.43 \pm 0.01$ & $2.51 \pm 0.01$ \\
\hline OL-AS & $93.67 \pm 0.21$ & $1.30 \pm 0.01$ & $0.08 \pm 0.00$ & $0.39 \pm 0.01$ & $2.31 \pm 0.01$ \\
\hline OL-EH & $93.88 \pm 0.27$ & $1.54 \pm 0.02$ & $0.08 \pm 0.00$ & $0.25 \pm 0.00$ & $1.57 \pm 0.01$ \\
\hline OL-LP & $97.02 \pm 0.56$ & $0.75 \pm 0.01$ & $0.11 \pm 0.01$ & $0.13 \pm 0.00$ & $2.37 \pm 0.01$ \\
\hline
\end{tabular}

* The values were shown as relative standard deviations of the replicates.

The physico-chemical properties of these five OLs were determined, including lignin hydrophobicity, zeta potential, and average particle size. The adsorption of rose bengal dye was used to assess the hydrophobicity of OLs (Lai et al. 2014; Huang et al. 2017). The analysis showed that the hydrophobicity of OL-CW, OL-BW, OL-AS, and OLLP were $0.93,0.90,0.75$, and $0.93 \mathrm{~L} / \mathrm{g}$, respectively (Table 2), which indicates that they were less hydrophobic than the corresponding OLs from the sulfuric acid catalyzed organosolv pretreatment (Huang et al. 2017). The highest hydrophobicity was observed in OL-EH $(1.09 \mathrm{~L} / \mathrm{g})$, which was obviously higher than the corresponding OL from the sulfuric acid catalyzed organosolv pretreatment (Huang et al. 2017). This might result in the strongest hydrophobic interaction between enzymes and OL-EH. The zeta potential analysis showed that the zeta potential of OL-CW, OL-BW, OL-AS, OL-EH, and OL-LP were $-9.73,-11.37,-10.63,-8.01$, and $-8.65 \mathrm{mV}$ at $\mathrm{pH} 4.8$, respectively. Acid catalysts showed slight impacts on the surface zeta potential of OLs. The higher absolute values of zeta potential indicated the higher negative charges on lignins. The negative charges on lignins are mainly due to the dissociation of functional groups in lignins, such as carboxyl groups (Lai et al. 2018). Additionally, SEM was utilized to observe the surface morphology of these OLs and showed that OL preparations clearly revealed spherical shaped lignin particles with a flattened surface (figure not shown). The same observation has been reported in the OLs from sulfuric acid catalyzed organosolv pretreatment in our previous study (Huang et al. 2017). Donohoe et al. (2008) also reported that round lignin droplets were attached on the cell wall surface after dilute acid or hot water pretreatment. It was apparent that the average particle sizes of OL-CW $(0.60 \mu \mathrm{m})$, OL-BW $(0.55 \mu \mathrm{m})$, and OLAS $(0.52 \mu \mathrm{m})$ were much larger than OL-EH $(0.24 \mu \mathrm{m})$ and OL-LP $(0.48 \mu \mathrm{m})$. The smaller particle size of the lignin results in greater accessible surface area, and thus there were more enzyme non-productive binding sites on lignins (Huang et al. 2017). Hence more enzyme adsorption might be observed on OL-EH and OL-LP samples.

Table 2. Hydrophobicity, Zeta Potential, and Particle Size of Organosolv Lignins

\begin{tabular}{|c|c|c|c|}
\hline Lignins & $\begin{array}{c}\text { Hydrophobicity } \\
(\mathrm{L} / \mathrm{g})\end{array}$ & $\begin{array}{c}\text { Zeta Potential } \\
(\mathrm{mV})\end{array}$ & $\begin{array}{c}\text { Average Particle } \\
\text { Size }(\mu \mathrm{m})\end{array}$ \\
\hline OL-CW & 0.93 & -9.73 & 0.60 \\
\hline OL-BW & 0.90 & -11.37 & 0.55 \\
\hline OL-AS & 0.75 & -10.63 & 0.52 \\
\hline OL-EH & 1.09 & -8.01 & 0.24 \\
\hline OL-LP & 0.93 & -8.65 & 0.48 \\
\hline
\end{tabular}

Besides the lignin physico-chemical properties, the structural differences in these five OLs were revealed by using 2D-HSQC NMR analysis. 
(a)
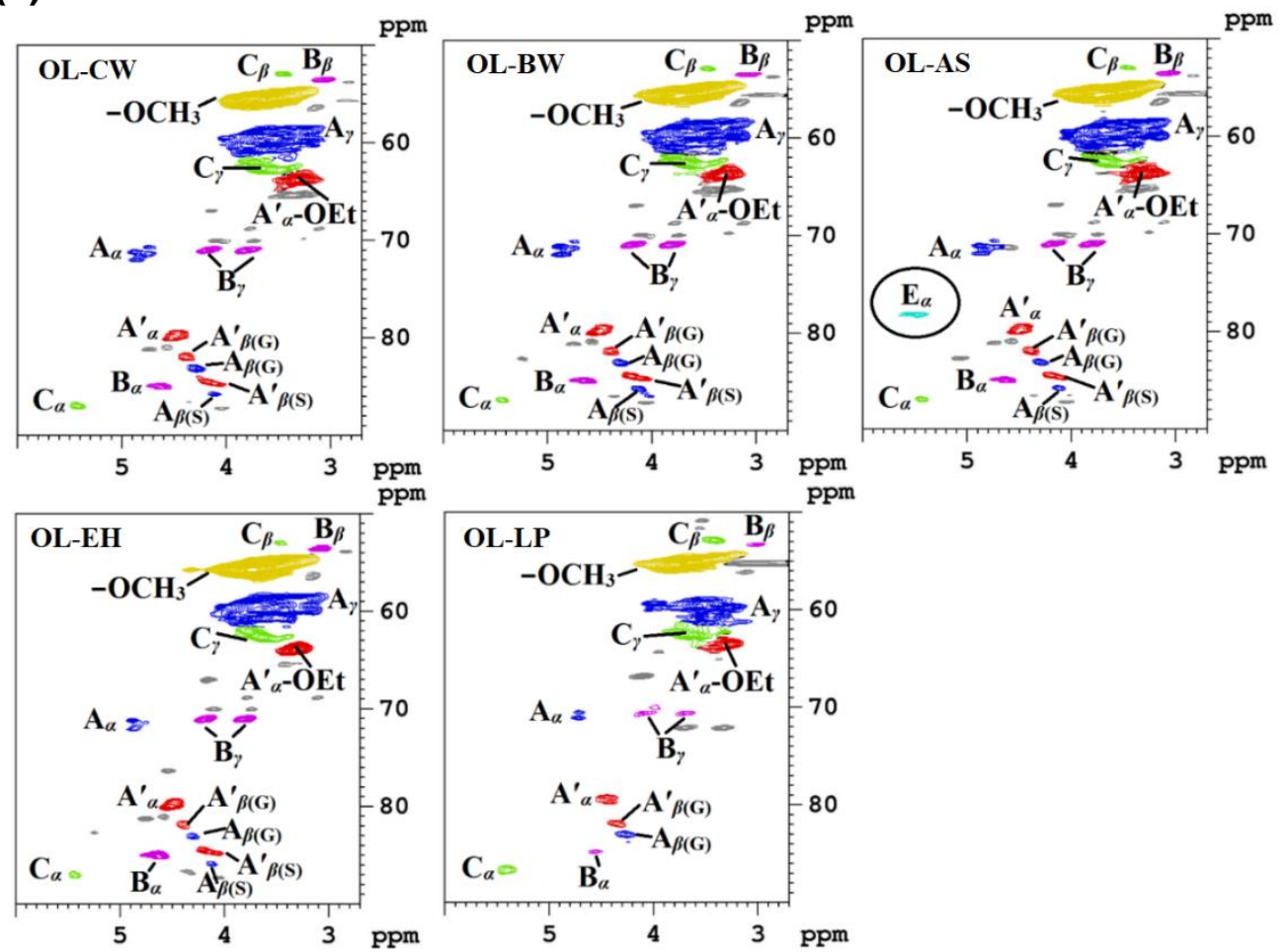

(b)
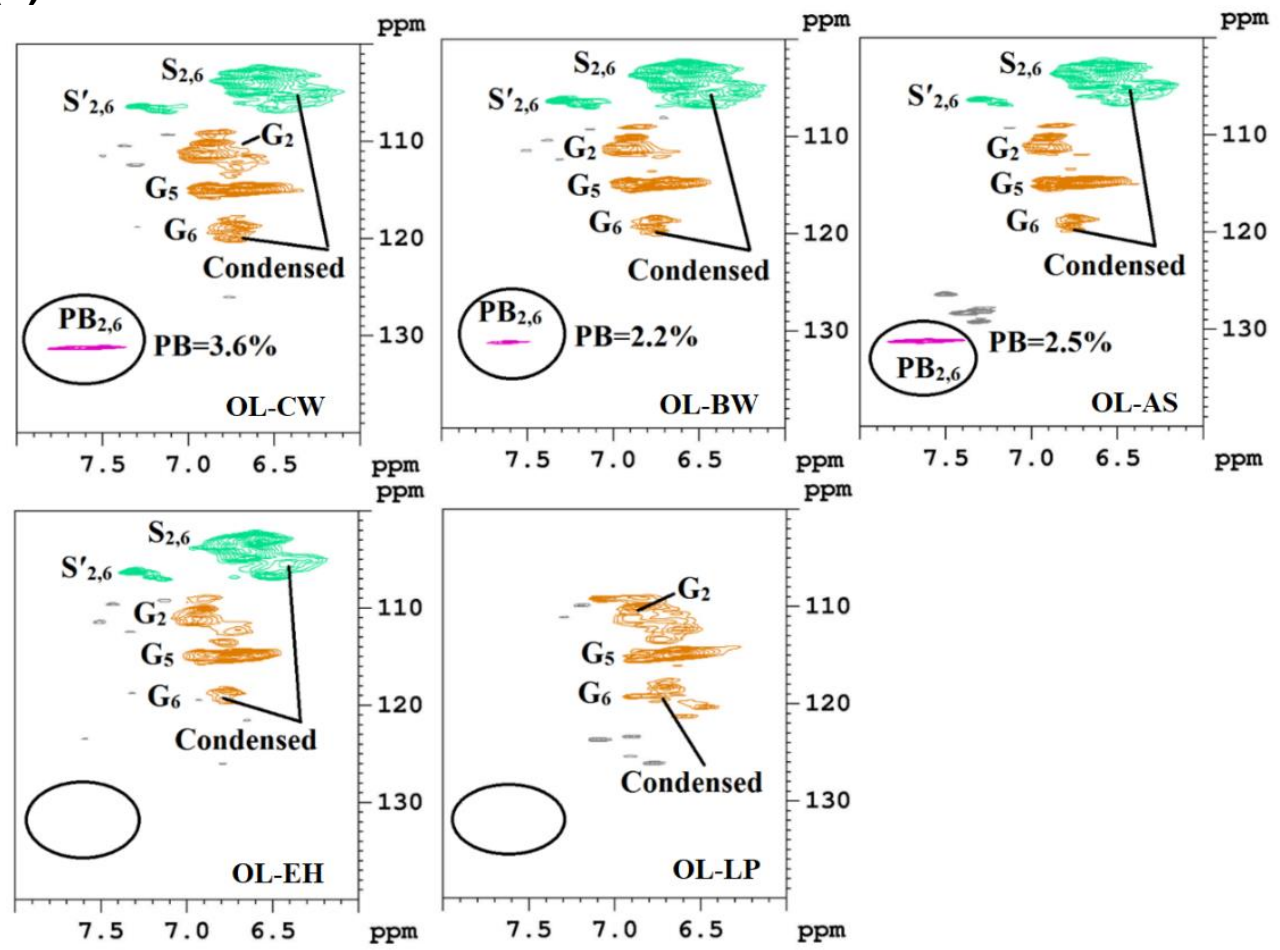

Fig. 1. 2D-HSQC NMR spectra of the OLs: (a) side-chain region, (b) aromatic region 
According to previous publications (Ralph et al. 2004; Del Rio et al. 2009; Wen et al. 2013; Sun et al. 2015), the cross-peaks at $\delta \mathrm{C} / \delta_{\mathrm{H}} 71.9 / 4.88\left(\mathrm{~A}_{\alpha}\right), 85.1 / 4.65\left(\mathrm{~B}_{\alpha}\right), 87.2 / 5.48$ $\left(\mathrm{C}_{\alpha}\right)$, and $78.3 / 5.57\left(\mathrm{E}_{\alpha}\right)$ were respectively referred to as the signals of inter-unit linkages in the lignins, including $\beta$-ether $(\mathrm{A}, \beta-O-4)$, resinol $(\mathrm{B}, \beta-\beta)$, phenylcoumaran $(\mathrm{C}, \beta-5)$, and $\alpha, \beta$-diaryl ether (E, $\alpha-O-4$ and $\beta-O-4$ ) (Fig. 1a and Fig. S1). In addition, the number of the inter-unit linkages per 100 aromatic units (Ar) in lignins was quantified by using the aromatic units as internal standard (Table 3). It was observed that the contents of $\beta-\mathrm{O}-4$ were reduced from an original $\sim 50$ per 100 Ar to 1.1-15.6 per $100 \mathrm{Ar}$ in five OLs, suggesting that the cleavage of $\beta-\mathrm{O}-4$ (depolymerization) is the predominant reaction during the organosolv pretreatment. As compared to the spectra of the original lignins $(\mathrm{Li}$ and Gellerstedt 2008), a new correlation at $\delta \mathrm{C} / \delta_{\mathrm{H}} 63.7 / 3.33$, which was referred to the methylene group in $\alpha$-ethoxylated $\beta$-O-4' (A'), appeared in the spectra of OLs. This indicated that these lignins were extensively ethoxylated at the $\alpha$-position of the lignin. A similar observation has been reported in the ethanol organosolv lignin from Buddleia davidii (Hallac et al. 2010). This might prevent the lignin condensation reaction during the organosolv pretreatment, since the ethoxylation chemically blocked the $\alpha$-carbonium ions on lignins (Lan and Luterbacher 2019). Both of the lignin depolymerization and the suppressed lignin condensation could be used to explain the obviously lower molecular weight in OL than original lignin.

Moreover, the signals of syringyl (S), guaiacyl (G), and p-hydroxybenzoate (PB) were clearly observed at $\delta_{\mathrm{C}} / \delta_{\mathrm{H}} 103.6 / 6.63\left(\mathrm{~S}_{2,6}\right), 110.7 / 6.93\left(\mathrm{G}_{2}\right), 115.4 / 6.78\left(\mathrm{G}_{5}\right)$, 118.8/6.73 (G6), 131.3/7.62 ( $\mathrm{PB}_{2,6}$ ), respectively in Fig. 1b. There was no signal of S-unit in OL-LP, since it is prepared from loblolly pine (softwood). The correlations from the condensed S- and G-units could be observed in Fig. 1b, suggesting that the lignin condensation occurred during the organosolv pretreatment. Moreover, S/G ratios of these five OLs were shown in Table 3. As compared to the OLs from pretreatment with sulfuric acid, OLs from pretreatment with hydrochloric acid had the relatively higher S/G ratios. Interestingly, the signals corresponding to $\mathrm{PB}$ units were observed in the spectra of OLCW, OL-AS, and OL-BW but not in OL-EH and OL-LP. The same observation has been reported in OLs from sulfuric acid catalyzed organosolv pretreatment (Huang et al. 2017). And the amount of PB (based on $\mathrm{S}_{2,6 / 2}+\mathrm{G}_{2}$ ) were also calculated and shown in Table 3. The carboxyl groups from PB units might contribute to the negative charges of lignins (Huang et al. 2017).

Table 3. Quantitative Analysis of Organosolv Lignins by 2D HSQC NMR

\begin{tabular}{|l|c|c|c|c|c|c|c|}
\hline Lignins & $\begin{array}{c}\beta-\mathrm{O}-4 \\
(\mathrm{~A})\end{array}$ & $\begin{array}{c}\beta-\mathrm{O}-4 \\
\left(\mathrm{~A}^{\prime}\right)\end{array}$ & $\beta-\beta$ & $\beta-5$ & $\begin{array}{c}\alpha-\mathrm{O}-4 / \\
\beta-\mathrm{O}-4\end{array}$ & S/G & PB (\%) \\
\hline OL-CW & 15.6 & 16.8 & 9.4 & 4.6 & N.D & 2.74 & 3.6 \\
\hline OL-BW & 13.5 & 15.2 & 10.3 & 1.9 & N.D & 10.45 & 2.2 \\
\hline OL-AS & 4.6 & 13.0 & 8.7 & 1.4 & 12.3 & 8.88 & 2.5 \\
\hline OL-EH & 1.1 & 5.3 & 6.9 & 0.9 & N.D & 2.44 & N.D \\
\hline OL-LP & 7.3 & 10.1 & 2.0 & 8.3 & N.D & N.D & N.D \\
\hline Amount of inter-unit linkages was expressed as per 100 Ar. \\
\hline
\end{tabular}

\section{Effects of Organosolv Lignins on Enzymatic Hydrolysis of MCC}

To evaluate the lignin effects on enzymatic hydrolysis, the five OLs (OL-CW, OLBW, OL-AS, OL-EH, and OL-LP) samples at $4 \mathrm{~g} / \mathrm{L}$ concentrations were added into the enzymatic hydrolysis of pure cellulose (MCC), respectively. The analysis indicated that 
the addition of OL-CW, OL-BW, and OL-AS increased the $72 \mathrm{~h}$ hydrolysis yield of MCC from $65.0 \%$ to $75.1 \%, 74.4 \%$, and $72.4 \%$, respectively (Fig. 2a). However, the addition of OL-EH and OL-LP decreased the $72 \mathrm{~h}$ hydrolysis yield from $65.0 \%$ to $44.6 \%$ and $61.8 \%$, respectively. OL-CW showed the highest positive effects on enzymatic hydrolysis, while OL-EH showed the highest inhibitory effects on enzymatic hydrolysis among these five OLs. The positive effects on enzymatic hydrolysis were also observed in OL-CW, OL-BW and OL-AS prepared from the pretreatment with sulfuric acid. However, OL-LP prepared from the pretreatment with sulfuric acid exhibited the stronger inhibition on enzymatic hydrolysis, as compared to that from pretreatment with hydrochloric acid (Huang et al. 2017). This could be due to the changes on OLs' physico-chemical properties when the acid catalyst was altered in the organosolv pretreatment. An obvious decline on the initial hydrolysis rate of MCC could be observed with the addition of OL-EH. This demonstrated that the five OLs could show contrasting effects on enzymatic hydrolysis of pure cellulose. A similar observation was reported in our previous studies (Lai et al. 2014; Huang et al. 2017). Normally, the softwood lignins were considered to be more inhibitory than the hardwood lignins (Lai et al. 2014; Pielhop et al. 2015). However, the present results indicated that the OL-EH derived from hardwood exhibited the stronger inhibition on enzymatic hydrolysis than OL-LP derived from softwood, potentially due to their enzymelignin interaction.
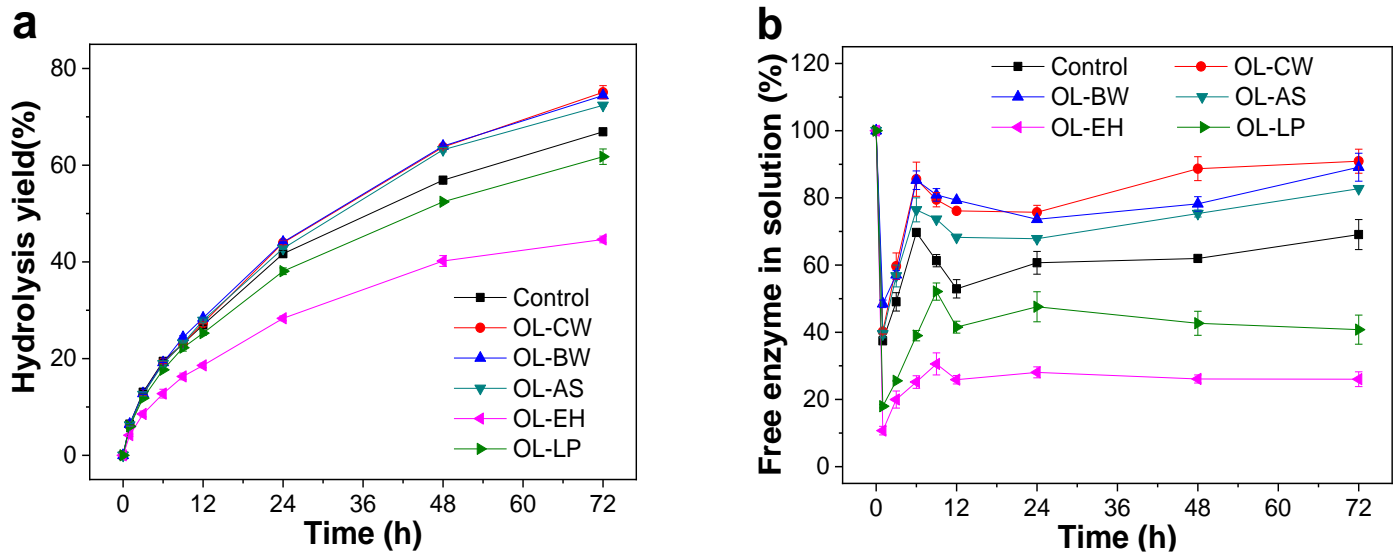

Fig. 2. Effect of the addition of OLs on enzymatic hydrolysis of MCC: (a) enzymatic hydrolysis; (b) enzyme distribution

Because the non-productive binding of enzyme on lignins played a considerable role in affecting enzymatic hydrolysis of pure cellulose (Lai et al. 2014; Sun et al. 2016), the enzyme distribution was examined during the enzymatic hydrolysis of MCC with or without lignin addition (Fig. 2b). The results showed that the free enzyme contents in all hydrolysis supernatants were dramatically dropped at the beginning, due to the rapid enzyme adsorption on cellulose or/and lignins. As the enzymatic hydrolysis proceeded, the free enzyme contents gradually increased at the latter stage of enzymatic hydrolysis, due to the release of enzyme after the cellulose hydrolysis. Interestingly, the obviously higher $72 \mathrm{~h}$ free enzyme contents were observed in hydrolysis supernatants of MCC with the addition of OL-CW, OL-BW, and OL-AS, as compared to the control (MCC only). The 72 $\mathrm{h}$ free enzyme contents increased from $69.0 \%$ to $90.9 \%, 89.1 \%$, and $82.7 \%$, respectively, after the addition of these three OLs. This increase in free enzyme contents suggested that the addition of OL-CW, OL-BW, and OL-AS surprisingly reduced the enzyme nonproductive binding on lignins, leading to the positive effects of these three OLs on 
enzymatic hydrolysis. Nevertheless, the addition of OL-EH and OL-LP respectively reduced the $72 \mathrm{~h}$ free enzyme contents from $69.0 \%$ (control) to $26.0 \%$ (with OL-EH) and $40.8 \%$ (with OL-LP). This indicated that the addition of OL-EH and OL-LP intensified the enzyme non-productive binding between enzyme and lignins, which agreed well with their negative effects on enzymatic hydrolysis of MCC. A strong correlation was established between the free enzyme contents in hydrolysis supernatants and hydrolysis yields at $72 \mathrm{~h}$ of hydrolysis $\left(\mathrm{R}^{2}=0.90\right)$. It was found that the higher the $72 \mathrm{~h}$ free enzyme contents were obtained, the higher were the $72 \mathrm{~h}$ hydrolysis yields. This confirmed that the lignin effects on enzymatic hydrolysis strongly depended on the lignin effects on cellulase distribution (Lai et al. 2014; Huang et al. 2017).

\section{Enzyme adsorption on Organosolv Lignins}

The enzyme distribution during hydrolysis of MCC with lignin addition was determined by the enzyme adsorption on both cellulose and lignin. Therefore, to evaluate the effects of enzyme-lignin interactions on enzymatic hydrolysis individually, the binding behavior between enzymes and five OLs were evaluated using their Langmuir adsorption isotherms (Table 4).

Table 4. Langmuir Adsorption Isotherm Parameters from Enzyme Adsorption on Organosolv Lignins

\begin{tabular}{|c|c|c|c|}
\hline Lignins & $\Gamma_{\max }(\mathrm{mg} / \mathrm{g})$ & $K(\mathrm{~mL} / \mathrm{mg})$ & $R(\mathrm{~L} / \mathrm{g})$ \\
\hline OL-CW & 2.646 & 4.357 & 0.012 \\
\hline OL-BW & 3.661 & 2.836 & 0.010 \\
\hline OL-AS & 3.031 & 2.824 & 0.009 \\
\hline OL-EH & 5.522 & 12.920 & 0.071 \\
\hline OL-LP & 7.499 & 3.280 & 0.025 \\
\hline
\end{tabular}

The Langmuir constant $(K)$ was incorporated with maximum adsorption capacity $\left(\Gamma_{\max }\right)$ into distribution coefficient $(R)$, which represented the binding strengths between lignins and enzymes (Nakagame et al. 2011; Sun et al. 2016). Specifically, $R$ values of OLCW, OL-BW, OL-AS, OL-EH, and OL-LP were 0.012, 0.010, 0.009, 0.071, and $0.025 \mathrm{~L} / \mathrm{g}$, respectively. A strong negative association was observed between the distribution coefficient and the corresponding $72 \mathrm{~h}$ hydrolysis yield $\left(\mathrm{R}^{2}=0.94\right.$, Fig. 3), which was consistent with the previous reports (Sun et al. 2016; Huang et al. 2017). It is well understood that the lignins (OL-EH and OL-LP) with higher enzyme distribution coefficient $(R)$ resulted in the inhibitory effects on enzymatic hydrolysis, potentially by reducing the enzymes activity and movability (Wang et al. 2020). However, the reasons why the lignins (OL-CW, OL-BW, and OL-AS) with lower enzyme distribution coefficient showed positive effects on enzymatic hydrolysis of pure cellulose are difficult to explain. It has been proposed that the lignin-based amphiphilic polymers could enhance the enzymatic hydrolysis of pure cellulose, and its underlying mechanism has been explored (Lin et al. 2019). The complex between enzymes and lignin-based amphiphilic polymers could be formed by hydrophobic interaction. Moreover, the hydrophobic phenylpropane structure of this complex acted as a cellulose binding domain to enhance the cellulase availability, thus enhancing the enzymatic hydrolysis of pure cellulose (Lin et al. 2019). Therefore, it is possible that the OLs with lower enzyme distribution coefficient acted as the lignin-based amphiphilic polymers and improved the enzymatic hydrolysis of cellulose. Similarly, OL-EH and OL-LP could form the enzyme-lignin complex, but the enzyme 
could be deactivated due to the much higher binding strength between these OLs and enzymes. In general, the enzymatic hydrolysis performances of MCC with lignin addition were mainly controlled by the interaction between enzyme and lignins. Understandings about the enzyme adsorption behavior on lignins could give insights into the lignin effects on enzymatic hydrolysis.

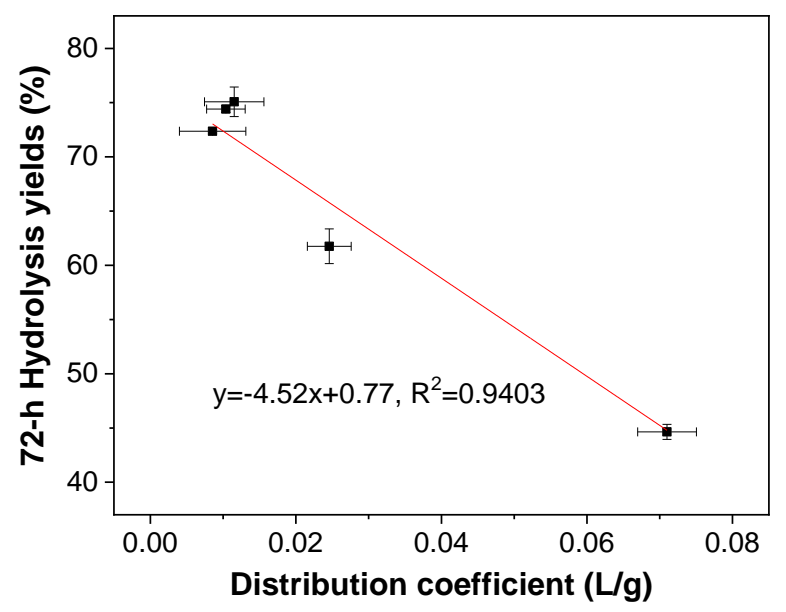

Fig. 3. Correlation between the enzyme distribution coefficient on the OLs and the corresponding $72 \mathrm{~h}$ hydrolysis yields of MCC

\section{Correlation between Lignin Properties and Its Enzyme Distribution Coefficient}

The interaction between enzyme and lignins occurs as a result of hydrophobic interaction, electrostatic interaction, and hydrogen bonding (Li and Zheng 2017). These interactions between lignins and enzymes could be dominated by the lignin properties, including hydrophobicity, zeta potential, particle size, and chemical structural features. Therefore, the correlation between lignin properties and its enzyme binding was investigated (Fig. 4). A positive correlation was observed between lignin hydrophobicity and distribution coefficient $(R)\left(\mathrm{R}^{2}=0.71\right.$, Fig. 4a), suggesting that the higher lignin hydrophobicity leads to the stronger hydrophobic interaction between enzyme and lignins. Among the five OLs, the highest hydrophobicity was observed in OL-EH $(1.09 \mathrm{~L} / \mathrm{g})$, contributing to its highest enzyme distribution coefficient $(0.071 \mathrm{~L} / \mathrm{g})$ and its strongest inhibition on enzymatic hydrolysis. The lignin modified to be more hydrophilic showed the much lower enzyme binding affinity (Ying et al. 2018; Lai et al. 2019a), which confirmed this observation that the hydrophobic interaction greatly affected the enzymelignin interaction.

Although the hydrophobicity of OL-LP and OL-CW was the same $(0.93 \mathrm{~L} / \mathrm{g})$, their distribution coefficients $(R)$ were entirely disparate (Table 4$)$. The underlying reason could be that electrostatic interactions have been also shown to influence the interaction between enzyme and lignins, besides hydrophobic interaction (Lou et al. 2013; Huang et al. 2017). Similarly, a relatively good correlation was observed between zeta potential of lignins and distribution coefficient $\left(\mathrm{R}^{2}=0.66\right.$, Fig. $\left.4 \mathrm{~b}\right)$. It was found that the higher negative charges on lignin could enhance the electrostatic repulsion between enzymes and lignins, thus reducing the enzyme binding strength on lignins (Lan et al. 2013; Lou et al. 2013). Previous reports proposed that the elevated hydrolysis $\mathrm{pH}$ could enhance the enzymatic 
hydrolysis of pretreated materials by increasing the negative charges on lignins and enzymes, thus enhancing the electrostatic repulsion between enzyme and lignin (Lan et al. 2013; Lai et al. 2018). Moreover, it has been reported that the metal ions such as calcium ion would form the lignin-metal complex, which might affect the binding between enzyme and lignin bearing carboxylate groups (Liu and Zhu 2010). In this study, the hydrophobicity of OL-LP and OL-CW was the same, but the obviously higher zeta potential was observed in OL-CW. The stronger electrostatic repulsion between OL-CW and enzyme could be used to explain the lower enzyme distribution coefficient of OL-CW. These results indicated that the lignin hydrophobicity and zeta potential may synergistically influence the enzyme distribution coefficient on lignin (Huang et al. 2017). Therefore, hydrophobicity and zeta potential as two independent variables were combined into the regression analysis with the distribution coefficient. A linear regression equation was obtained $\left(y=116.20 \times\right.$ hydrophobicity $+8.01 \times$ zeta potential $\left.-4.00, \mathrm{R}^{2}=0.79\right)$ between the enzyme distribution coefficient with hydrophobicity and zeta potential. The results confirm the conclusion of Yoon et al. (1998) that electrostatic interaction and hydrophobic interaction synergistically control the protein adsorption. Additionally, the distribution coefficient of the OLs was also correlated well with their average particle size $\left(R^{2}=0.94\right.$, Fig. 4c). It was demonstrated that the smaller particle size of the lignin had the greater accessible surface area, which leads to the more enzyme non-productive binding sites on lignins, thus the stronger enzyme binding strength.
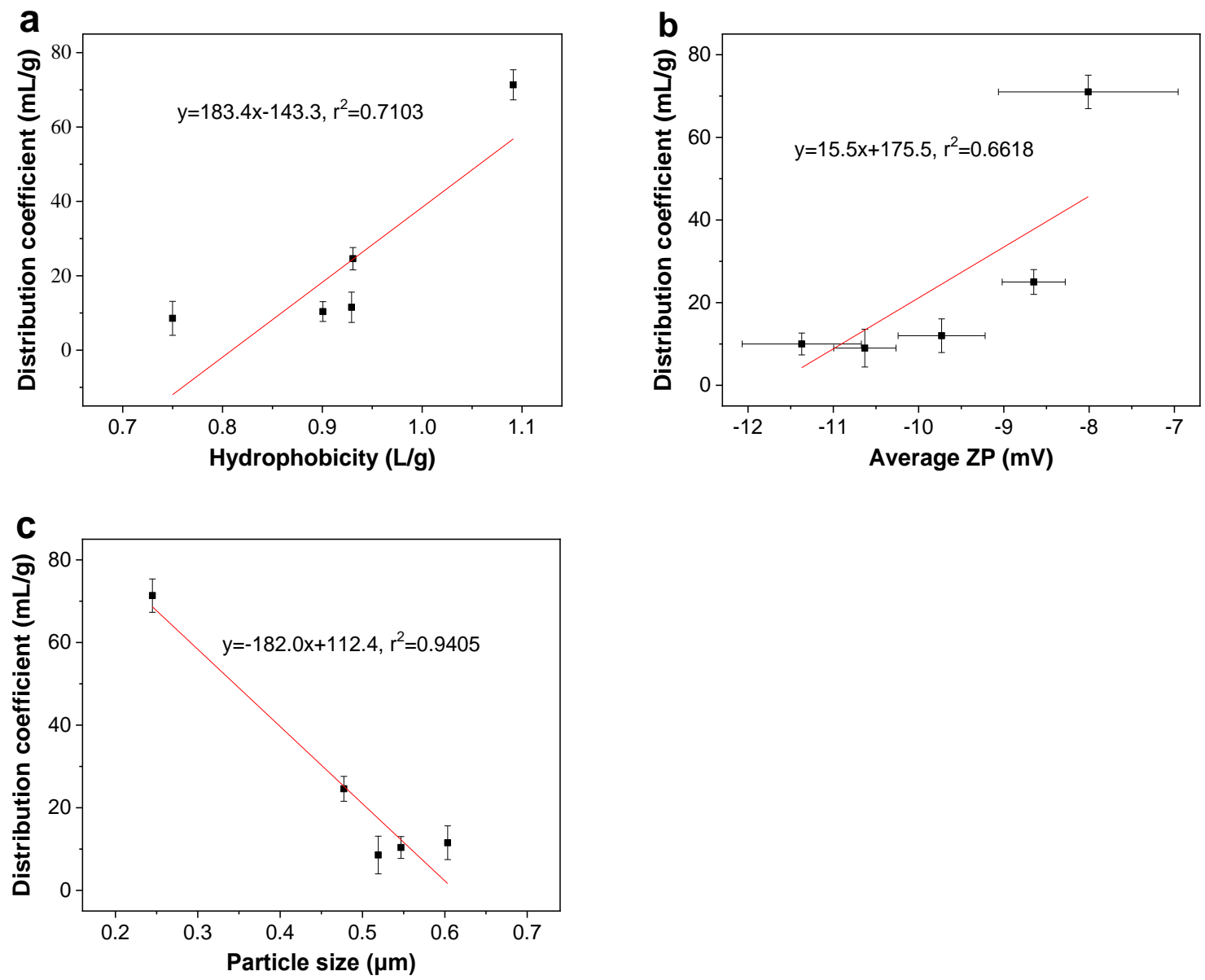

Fig. 4. Correlation between the lignin properties and the enzyme distribution coefficient on the OLs: (a) hydrophobicity; (b) average zeta potential; and (c) particle size 
The relation between the lignin structural features and the enzyme distribution coefficient or the lignin inhibition on enzymatic hydrolysis has been investigated in the previous studies (Huang et al. 2017). An association was observed between the lignin inhibition and the condensed lignin moieties (such as condensed phenolic moieties and $\beta$ $\beta$ or $\beta$-5 linkages) (Sun et al. 2016; Lai et al. 2019b). The condensed substructures in lignins were considered to enhance the hydrophobic interaction between enzymes and lignins. Moreover, it has been reported that the higher content of S/G in lignins led to the lower lignin recalcitrance in enzymatic hydrolysis (Yoo et al. 2018). However, the correlation between the condensed lignin moieties or S/G ratio and the enzyme distribution coefficient was not observed in this study. It should be noted that the OL lignins with PB units enhanced enzymatic hydrolysis of MCC, while those without PB units showed the negative effects. A similar observation was reported in our previous study (Huang et al. 2017). This could be due to the partial negative charges on the carbonyl groups in PB units, which led to the lower enzyme binding on lignins. Generally, the correlation between lignin properties and the enzyme distribution coefficient on lignin in this study revealed that the lignin hydrophobicity and zeta potential synergistically influenced the enzyme-lignin interaction. The lignin particle size also played a significant role in controlling the enzyme adsorption on lignins. These could be the main reasons to explain the role of lignins in enzymatic hydrolysis, which also suggests that reducing lignin hydrophobicity, increasing lignin negative charges, or increasing the lignin particle sizes could effectively relieve the lignin inhibition on enzymatic hydrolysis.

\section{CONCLUSIONS}

1. When the acid catalyst was altered in the organosolv pretreatment, the properties of the resultant organosolv lignins (OLs) varied, which led to their disparate effects on enzymatic hydrolysis. However, similar correlations between lignin properties and their effects on enzymatic hydrolysis could be established.

2. Both positive and negative effects of OLs addition on enzymatic hydrolysis of MCC were observed.

3. A strong correlation between the enzyme distribution coefficient on lignins and the 72 $\mathrm{h}$ hydrolysis yields indicated that the enzymatic hydrolysis of MCC with lignin addition were mainly controlled by the enzyme-lignin interaction.

4. The lignin with lower hydrophobicity, higher zeta potential, and higher particle size possessed the lower enzyme distribution coefficient, thereby showing the less inhibitory effects on enzymatic hydrolysis.

\section{ACKNOWLEDGMENTS}

The study was supported in part by grants from National Natural Science Foundation of China (31971606). Huang's study was also partially supported by USDA NIFA (Grant No. 2011-68005-30410), the Guangdong Basic and Applied Basic Research Foundation (2019A1515011898) and the Priority Academic Program Development of Jiangsu Higher Education Institution (PAPD). 


\section{REFERENCES CITED}

Adel, A. M., El-Wahab, Z. H. A., Ibrahim, A. A., and Al-Shemy, M. T. (2010). "Characterization of microcrystalline cellulose prepared from lignocellulosic materials. Part I. Acid catalyzed hydrolysis,” Bioresour. Technol. 101(12), 4446-4455. DOI: 10.1016/j.biortech.2010.01.047.

Berlin, A., Balakshin, M., Gilkes, N., Kadla, J., Maximenko, V., Kubo, S., and Saddler, J. (2006). "Inhibition of cellulase, xylanase and $\beta$-glucosidase activities by softwood lignin preparations,” J. Biotechnol. 125, 198-209. DOI: 10.1016/j.jbiotec.2006.02.021

Bradford, M. M. (1976). "A rapid method for the quantitation of microgram quantities of protein utilizing the principle of protein-dye binding," Anal. Biochem. 72(1-2), 248254. DOI: 10.1016/0003-2697(76)90527-3

Del Rio, J. C., Rencoret, J., Marques, G., Li, J., Gellerstedt, G., Jiménez-Barbero, J., Martínez, A. N. T., and Gutiérrez, A. (2009). "Structural characterization of the lignin from jute (Corchorus capsularis) fibers," J. Agric. Food Chem. 57(21), 10271-10281. DOI: $10.1021 /$ jf900815x

Donohoe, B. S., Decker, S. R., Tucker, M. P., Himmel, M. E., and Vinzant, T. B. (2008). "Visualizing lignin coalescence and migration through maize cell walls following thermochemical pretreatment," Biotechnol. Bioeng. 101(5), 913-925. DOI: 10.1002/bit.21959

Grabber, J. H., Ralph, J., Lapierre, C., and Barrière, Y. (2004). "Genetic and molecular basis of grass cell-wall degradability. I. Lignin-cell wall matrix interactions," C. $R$. Biol. 327(5), 455-465. DOI: 10.1016/j.crvi.2004.02.009

Hallac, B. B., Pu, Y., and Ragauskas, A. J. (2010). "Chemical transformations of Buddleja davidii lignin during ethanol organosolv pretreatment," Energy Fuels 24(4), 2723 2732. DOI: $10.1021 / \mathrm{ef} 901556 \mathrm{u}$

Heredia-Olea, E., Pérez-Carrillo, E., and Serna-Saldívar, S.O. (2012). "Effects of different acid hydrolyses on the conversion of sweet sorghum bagasse into C5 and C6 sugars and yeast inhibitors using response surface methodology," Bioresour. Technol. 119, 216-223. DOI: 10.1016/j.biortech.2012.05.122

Huang, Y., Sun, S., Huang, C., Yong, Q., Elder, T., and Tu, M. (2017). "Stimulation and inhibition of enzymatic hydrolysis by organosolv lignins as determined by zeta potential and hydrophobicity," Biotechnol. Biofuels 10(1), 162. DOI: 10.1186/s13068017-0853-6

Kumar, L., Arantes, V., Chandra, R., and Saddler, J. (2012). "The lignin present in steam pretreated softwood binds enzymes and limits cellulose accessibility," Bioresource Technol. 103(1), 201-208. DOI: 10.1016/j.biortech.2011.09.091

Lai, C., Jia, Y., Wang, J., Wang, R., Zhang, Q., Chen, L., Shi, H., Huang, C., Li, X., and Yong, Q. (2019a). "Co-production of xylooligosaccharides and fermentable sugars from poplar through acetic acid pretreatment followed by poly (ethylene glycol) ether assisted alkali treatment," Bioresource Technol. 288, 121569. DOI: 10.1016/j.biortech.2019.121569

Lai, C., Yang, B., Lin, Z., Jia, Y., Huang, C., Li, X., Song, X., and Yong, Q. (2019b). "New strategy to elucidate the positive effects of extractable lignin on enzymatic hydrolysis by quartz crystal microbalance with dissipation," Biotechnol. Biofuels 12(1), 57. DOI: 10.1186/s13068-019-1402-2

Lai, C., Tu, M., Qiang, Y., and Yu, S. (2018). "Synergistic effects of pH and organosolv lignin addition on the enzymatic hydrolysis of organosolv-pretreated loblolly pine,"

Huang et al. (2020). "Organosolv lignin \& hydrolysis," BioResources 15(4), 8909-8924. 8922 
RSC Adv. 8(25), 13835-13841. DOI: 10.1039/C8RA00902C

Lai, C., Tu, M., Shi, Z., Ke, Z., Olmos, L. G., and Yu, S. (2014). "Contrasting effects of hardwood and softwood organosolv lignins on enzymatic hydrolysis of lignocellulose," Bioresource Technol. 163(7), 320-327. DOI: 10.1016/j.biortech.2014.04.065

Lan, T., Lou, H., and Zhu, J. (2013). "Enzymatic saccharification of lignocelluloses should be conducted at elevated pH 5.2-6.2," BioEnergy Res. 6(2), 476-485. DOI: 10.1007/s12155-012-9273-4

Lan, W., and Luterbacher, J. S. (2019). "Preventing lignin condensation to facilitate aromatic monomer production," CHIMIA Int. J. Chem. 73(7-8), 591-598. DOI: 10.2533/chimia.2019.591

Li, J., and Gellerstedt, G. (2008). "Improved lignin properties and reactivity by modifications in the autohydrolysis process of aspen wood," Ind. Crops Prod. 27(2), 175-181. DOI: 10.1016/j.indcrop.2007.07.022

Li, M., Pu, Y., and Ragauskas, A. J. (2016). "Current understanding of the correlation of lignin structure with biomass recalcitrance," Front. Chem. 4, 45. DOI: 10.3389/fchem.2016.00045

Li, X., and Zheng, Y. (2017). "Lignin-enzyme interaction: Mechanism, mitigation approach, modeling, and research prospects," Biotechnol. Adv. 35(4), 466-489. DOI: 10.1016/j.biotechadv.2017.03.010

Lin, X., Wu, L., Huang, S., Qin, Y., Qiu, X., and Lou, H. (2019). “Effect of lignin-based amphiphilic polymers on the cellulase adsorption and enzymatic hydrolysis kinetics of cellulose," Carbohydr. Polym. 207, 52-58. DOI: 10.1016/j.carbpol.2018.11.070

Liu, H., and Zhu, J. Y. (2010). "Eliminating inhibition of enzymatic hydrolysis by lignosulfonate in unwashed sulfite-pretreated aspen using metal salts," Bioresour. Technol. 101(23), 9120-9127. DOI: 10.1016/j.biortech.2010.07.035.

Lou, H., Zhu, J. Y., Lan, T. Q., Lai, H., and Qiu, X. (2013). “pH-Induced lignin surface modification to reduce nonspecific cellulase binding and enhance enzymatic saccharification of lignocelluloses," ChemSusChem 6(5), 919-927. DOI: 10.1002/cssc.201200859

Meunier-Goddik, L., and Penner, M. H. (1999). "Enzyme-catalyzed saccharification of model celluloses in the presence of lignacious residues," J. Agric. Food Chem. 47, 346-351. DOI: 10.1021/jf980407b

Nakagame, S., Chandra, R. P., Kadla, J. F., and Saddler, J. N. (2011). "Enhancing the enzymatic hydrolysis of lignocellulosic biomass by increasing the carboxylic acid content of the associated lignin," Biotechnol. Bioeng. 108, 538-548. DOI: 10.1002/bit.22981

Öhgren, K., Bura, R., Saddler, J., and Zacchi, G. (2007). "Effect of hemicellulose and lignin removal on enzymatic hydrolysis of steam pretreated corn stover," Bioresource Technol. 98(13), 2503-2510. DOI: 10.1016/j.biortech.2006.09.003

Pan, X. (2008). "Role of functional groups in lignin inhibition of enzymatic hydrolysis of cellulose to glucose," J. Biobased Mater. Bioenergy 2(1), 25-32. DOI: 10.1166/jbmb.2008.005

Pielhop, T., Larrazábal, G. O., Studer, M. H., Brethauer, S., Seidel, C. M., and von Rohr, P. R. (2015). "Lignin repolymerisation in spruce autohydrolysis pretreatment increases cellulase deactivation," Green Chem. 17(6), 3521-3532. DOI: 10.1039/C4GC02381A

Ralph, J., Lundquist, K., Brunow, G., Lu, F., Kim, H., Schatz, P. F., Marita, J. M., 
Hatfield, R. D., Ralph, S. A., and Christensen, J. H. (2004). "Lignins: Natural polymers from oxidative coupling of 4-hydroxyphenyl-propanoids," Phytochem. Rev. 3(1-2), 29-60. DOI: 10.1023/B:PHYT.0000047809.65444.a4

Sluiter, A., Hames, B., Ruiz, R., Scarlata, C., Sluiter, J., Templeton, D., and Crocker, D. (2012). "Determination of structural carbohydrates and lignin in biomass: Laboratory analytical procedures (LAP)," National Renewable Energy Laboratory. 2012; Technical Report: NREL/TP-510-42618.

Sun, S., Wen, J., Sun, S., and Sun, R. C. (2015). "Systematic evaluation of the degraded products evolved from the hydrothermal pretreatment of sweet sorghum stems," Biotechnol. Biofuels 8(1), 37. DOI: 10.1186/s13068-015-0223-1

Sun, S. L., Huang, Y., Sun, R. C., and Tu, M. (2016). "Strong association of condensed phenolic moieties in isolated lignins with their inhibition of enzymatic hydrolysis," Green Chem. 18(15) , 4276-4286. DOI: 10.1039/C6GC00685J

Wang, Z., Zhu, J., Fu, Y., Qin, M., Shao, Z., Jiang, J., and Yang, F. (2013). "Lignosulfonate-mediated cellulase adsorption: enhanced enzymatic saccharification of lignocellulose through weakening nonproductive binding to lignin," Biotechnol. Biofuels 6, 156. DOI: 10.1186/1754-6834-6-156

Wang, J., Hao, X., Wen, P., Zhang, T., and Zhang, J. (2020). “Adsorption and desorption of cellulase on/from lignin pretreated by dilute acid with different severities," Ind. Crops Prod. 148, 112309. DOI: 10.1016/j.indcrop.2020.112309

Wen, J. L., Sun, S. L., Xue, B. L., and Sun, R. C. (2013). "Recent advances in characterization of lignin polymer by solution-state nuclear magnetic resonance (NMR) methodology," Materials 6(1), 359-391. DOI: 10.3390/ma6010359

Ying, W., Shi, Z., Yang, H., Xu, G., Zheng, Z., and Jing, Y. (2018). "Effect of alkaline lignin modification on cellulase-lignin interactions and enzymatic saccharification yield," Biotechnol. Biofuels 11(1), 214. DOI: 10.1186/s13068-018-1217-6

Yoo, C. G., Dumitrache, A., Muchero, W., Natzke, J., Akinosho, H., Li, M., Sykes, R. W., Brown, S. D., Davison, B., Tuskan, G. A., Pu, Y., and Ragauskas, A. J. (2018).

"Significance of lignin $\mathrm{S} / \mathrm{G}$ ratio in biomass recalcitrance of Populus trichocarpa variants for bioethanol production," ACS Sustainable Chem. Eng. 6(2), 2162-2168. DOI: 10.1021/acssuschemeng.7b03586

Yoo, C. G., Meng, X., Pu, Y., and Ragauskas, A. J. (2020). “The critical role of lignin in lignocellulosic biomass conversion and recent pretreatment strategies: A comprehensive review," Bioresource Technol. 301, 122784. DOI: 10.1016/j.biortech.2020.122784

Yoon, J. Y., Lee, J. H., Kim, J. H., and Kim, W. S. (1998). "Separation of serum proteins with uncoupled microsphere particles in a stirred cell," Colloids Surf. B 10(6), 365377. DOI: 10.1016/S0927-7765(97)00068-4

Yu, Z., Gwak, K. S., Treasure, T., Jameel, H., Chang, H. M., and Park, S. (2014). "Effect of lignin chemistry on the enzymatic hydrolysis of woody biomass," ChemSusChem 7(7), 1942-1950. DOI: $10.1002 /$ cssc.201400042

Article submitted: May 1, 2020; Peer review completed: July 25, 2020; Revised version received: October 3, 2020; Accepted: October 4, 2020; Published: October 12, 2020. DOI: $10.15376 /$ biores.15.4.8909-8924 